\title{
CALCULATION OF STRENGTH OF CONCRETE FILLED STEEL BOX COLUMNS
}

\author{
Krishan A.L ${ }^{1}$, Troshkina E.A ${ }^{2}$, Krishan M.A ${ }^{3}$ \\ ${ }^{1}$ Department of Building Constructions, Magnitogorsk State Technical University, Russia \\ ${ }^{2}$ Department of Building Constructions, Magnitogorsk State Technical University, Russia \\ ${ }^{3}$ Department of Building Constructions, Magnitogorsk State Technical University, Russia
}

\begin{abstract}
The experimental - theoretical researches of concrete filled steel box columns (CFSBC) with pressed structure of concrete are executed. It is offered to make the CFSBC with preliminary pressed concrete core to improve their construction. The bearing capacity of centrally compressed samples of CFSBC has increased by $10 \div 15 \%$. The received results are explained by the significant increase of the strength of concrete core in the preliminary compressed CFSBC samples due to the simultaneous display of three effects: long-term compression of concrete mix, preliminary lateral compression of concrete core and its work in the conditions of volume compression. The calculation of strength of CFSBC should be carried out on the basis of nonlinear deformation model of reinforced concrete. Three-axis tensely - deformed conditions are accepted for the analytical description of work of concrete core and external steel holder. Nonuniformity of stress state of concrete and bending of walls of external steel holder are taken into account. The basic dependences, which allow to carry out the approximate calculations of the strength of compressed CFSBC on limiting efforts, are also resulted.
\end{abstract}

Keywords: concrete filled steel box columns, preliminary pressed, concrete core, bearing capacity, calculation of strength

\section{INTRODUCTION}

Concrete filled steel tube columns (CFST) of circular cross section are used in building industry more often than concrete filled steel box columns (CFSBC) of square crosssection. It is partly connected with a greater availability of large-scale round tubes. Another reason is noticeably less casing effect in the columns of square cross-section, which is not usually taken into account in strength calculations. Concrete filled steel box columns of square cross-section are less efficient because of the local bending of side walls of steel holder, which leads to the decrease of transversal stresses in the concrete core.

However, concrete filled steel tube columns of circular cross section also have some drawbacks. Thus, their bearing capacity decreases with the increase of eccentricity of compressive load application. It is caused by geometric characteristics of their cross-section. CFSTs of circular cross-sections of the same dimensions have greater flexibility due to smaller radius of gyration.

Most researches of concrete filled steel box columns of square cross-section were carried out in Asia and Australia [1-6]. Such experiments were also carried out in Russia [79]. Analysis of the results of these researches shows that casing effect is quite noticeable in CFSBC of square crosssection. Compared with traditional reinforced concrete elements concrete filled steel box samples of square crosssection turned out to be stronger (according to different references) from 1.01 to 1.3 times. It is explained by the increase of the concrete core strength due to its lateral compression.

Further researches of bearing capacity of square cross section CFSBC are of great interest because these investigations provide a greater choice in the design process of buildings for design engineers. The purpose of these researches is the development of the calculation procedure of bearing capacity, taking into account the main features of volume-stressed concrete core and steel holder behavior.

At the same time it is necessary to improve the effectiveness of CFSBC of square cross section. In particular, it is proposed to produce them with a preliminary compression of the concrete core due to the long-term compression of the concrete mixture. This manufacturing technique is described in paper [10].

\section{THE BASIC RESULTS OF EXPERIMENTAL RESEARCH}

Experimental research of laboratory samples at axial and eccentric compression were carried out to test the effectiveness of preliminary compressed concrete filled steel box columns of the offered design. Twenty two series of samples were manufactured: 4 series with cross-sectional dimensions of $180 \times 180 \mathrm{~mm}, 10$ series with cross-sectional dimensions of $160 \times 160 \mathrm{~mm}$ and 8 series with cross-sectional dimensions of $100 \times 100 \mathrm{~mm}$. Three twin samples were the basis of each series. Ratio of the section side of to its length was approximately 1/4. Ten samples were manufactured 
with a core made of traditional concrete, five samples - with a core made of pressed concrete, seven samples - with a core made of self-stressing concrete. The variants of manufacturing of concrete filled steel box columns of square section are shown in Fig. 1.

The samples were tested in a vertical position at the age of 60 days by means of a hydraulic press applying the shortterm compressive load. Relative eccentricities of the compressive force $e_{0} / b$ were $e_{0} / b=0,0.125,0.25,0.5$, 0.75 .

In order to identify the proportion of the bending component of the total deformation of the pipe wall four series of short laboratory samples of concrete filled steel box columns of square cross section were made. The samples were steel pipes with cross section $140 \times 140 \mathrm{~mm}$ and with wall thickness of $4 \mathrm{~mm}$, made of steel with the yield point of 360 $\mathrm{MPa}$ and $440 \mathrm{MPa}$, filled with heavy concrete with the prism strength of 30 and $60 \mathrm{MPa}$. The height of the samples was $560 \mathrm{~mm}$.
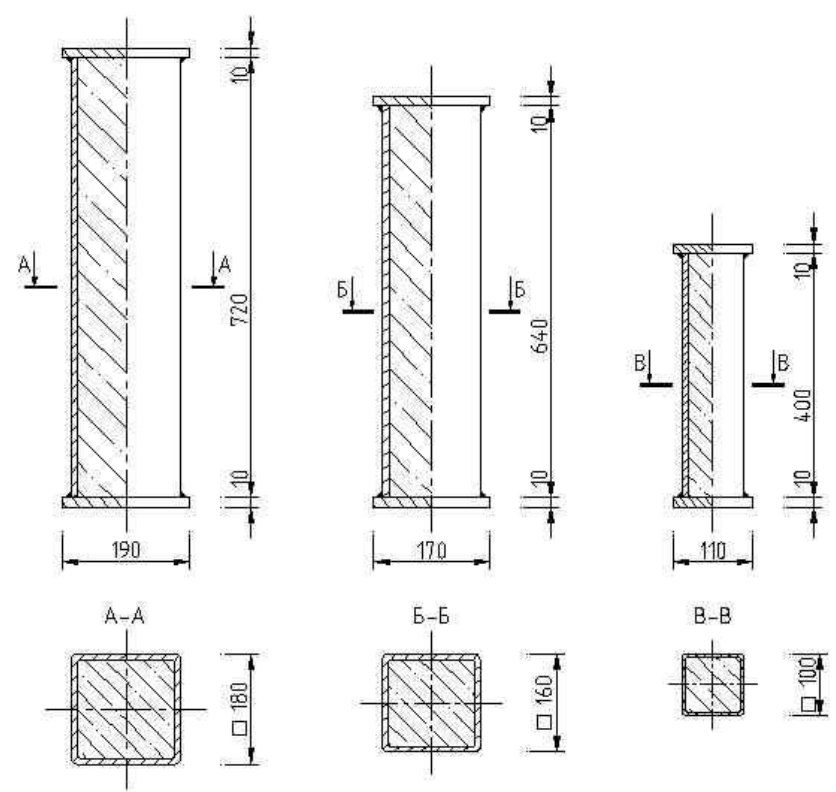

Fig. 1: Variants of manufacturing of laboratory samples of concrete filled steel box columns of square cross-section

The experimental results showed that the casing effect took place in the samples of all series. The increase of bearing capacity in the samples without compression was on average $10 \%$, in the samples made of self-stressing concrete - $16 \%$ and in the samples with the core made of pressed concrete $25 \%$ in comparison with traditional reinforced concrete elements. The increase of strength of the not compressed concrete samples was $30 \%$ and the increase of strength of the preliminary compressed samples made of pressed concrete was $74 \%$.

Preliminary compression of the concrete core had progressively smaller influence on the bearing capacity of CFSBC with the growth of relative eccentricity of compressive load. This effect was noticeable only when $\mathrm{e}_{0} / \mathrm{b}$ $\leq 0,25$ and it was particularly significant at eccentricities located within the cross-section core.

The results of processing the experimental data received during the experimental research of the stress-strain state of the holder wall of CFSBC showed that the proportion of tensile strains was $70 \div 85 \%$, the proportion of flexural strains was $15 \div 30 \%$.

\section{CALCULATION OF STRENGTH OF CONCRETE FILLED STEEL BOX COLUMNS}

The strength calculation procedure for CFSBC based on the model of nonlinear deformation is the most reliable one taking into account the type of reinforcement of CFSBC. One great advantage of the deformation model is a single system approach to the calculation of bearing capacity and evaluation of stress-strain state of the elements at all stages of their behavior in different modes and loading schemes. Practical implementation of this model is carried out by the iterative calculation which is carried out taking into account the inelastic deformations of materials and changes of the coefficients of transverse strains in the core and in the holder with the increase of the stress level [10]. It is necessary to know the dependences between stresses and relative strains for concrete and steel.

The concrete core and the steel holder of CFSBC are in the condition of volume stress state. The indicated dependences are unknown before the calculation procedure. In this regard, the calculation of bearing capacity should be carried out in two stages:

- In the first stage the correlations $" \sigma_{b z}-\varepsilon_{b z}$ » of the concrete core and $" \sigma_{p z}-\varepsilon_{p z} »$ of the steel tubular holder are analytically determined for the axial direction (along the axis « $\mathrm{Z} »)$. So, at first the calculation of strength of the normal section of short centrally compressed CFSBC, which has similar geometric and structural parameters to the initial data of the solved task, is carried out;

- In the second stage the calculation of the eccentrically compressed steel-concrete element strength is carried out with the help of known dependences of the nonlinear deformation model (according to SP 63.13330 .2012 or other normative literature).

The coordinates of the parametric points of the deformation diagrams of the concrete core $" \sigma_{b z}-\varepsilon_{b z} »$ and the steel holder $« \sigma_{p z}-\varepsilon_{p z} »$ are determined before carrying out the first stage of the calculation in the first approximation.

When the calculation of concrete filled steel tube columns of circular cross section is carried out, the assumption is usually made that the lateral pressure of the steel holder on the concrete core, which takes place at the action of axial load along the axis « $\mathrm{Z} »$, is considered to be distributed uniformly over the normal section. The character of the change of the main transverse stresses in the concrete core section of CFSBC of square cross-section was identified on 
the basis of analysis of the results of numerical researches of steel-concrete elements of rectangular cross section carried out by E.D.Chikhladze [11].

The zone of volume compression was identified in the central part of the cross section of all samples, in which transverse stresses were almost identical in value to the analogous stresses of concrete filled steel tube columns of circular cross section with the same constructive coefficients:

$$
\rho=\frac{\sigma_{y} A_{p}}{R_{b} A},
$$

where $\sigma_{y}$ and $A_{p}$ - the yield point and the cross-section area of the steel holder;

$R_{b}$ and $A$ - compressive strength of concrete and its crosssection area.

The value of the central zone of volume compression is mainly determined by the relation between the width of the cross section $b$ and the thickness of the steel holder $\delta$. The influence of strength characteristics of the steel holder and the concrete core on the value of the central zone turned out to be much smaller and it was decided not to take it into account in the calculations.

The central zone is surrounded by the area in which concrete works in less favorable conditions because of the stress redistribution due to moving from the center of gravity of the cross section. In this area the modulus-minimal compressive stresses gradually reduce to zero at the boundary with the third zone. The law of change of these stresses (in the strength reserve) is accepted to be linear.

In the third zone, which is located at the periphery of the cross section of the concrete core of CFSBC, concrete behaves in the least favorable conditions of compression along the two principal axes and of tension along the third one.

The angular zones are distinguished in the cross-section of the steel holder, where tensile stresses of tangential direction mainly take place, and also the central areas are distinguished on the side edges of the column, in which bending stress state takes place.

Taking into account the complex stress state of the system "concrete core - steel holder", the following simplifying assumptions are accepted for calculations:

- transverse stresses in the concrete core are considered to be equal across the section and they are equal to the averaged equivalent stress, and the coefficient $\xi$ is introduced in the calculation. Heterogeneity of the main stresses distribution over the normal cross section of the concrete core is taken into account by the coefficient $\xi(0 \leq \xi \leq 1)$;
- the steel holder is considered to be tensioned in the cross section because of the action of averaged stresses in the concrete core. Wall bending is taken into account by decreasing the calculated resistance of steel when multiplying it by the factor of working conditions $\gamma_{p}$.

The analysis of the results of the carried out research, as well as the published data of Japanese researchers [3] made it possible to offer the following dependences for calculating the coefficients $\gamma_{p}$ and $\xi$ :

$$
\begin{gathered}
\gamma_{p}=\alpha_{1} \cdot \alpha_{2} \\
\xi=(1-0,01 b / \delta)^{2} \geq 0,
\end{gathered}
$$

where $\alpha_{1}$ - coefficient which determines the share of the tensile component in the total deformation of the holder wall in the limit state of CFSB (it is recommended to be taken $\alpha_{1}=0,7$ );

$\alpha_{2}$ - coefficient which takes into account the value of strengthening of cold-formed profiles $\left(\alpha_{2}=1,1\right.$ - for the steel holder made of cold-formed profiles $\alpha_{2}=1,1$, in other cases, $\alpha_{2}=1$ );

$b$ and $\delta$ - width and thickness of the steel holder wall.

The coefficient $\xi$ is equal to zero for the values of $b / \delta \geq 100$.

Justification of the formulas (2) and (3) is given in paper [4].

Taking into account the accepted assumptions and the offered coefficients $\gamma_{p}$ and $\xi$, the strength of the concrete core $R_{b m}$ can be calculated by the formula earlier developed by A.L. Krishan for concrete filled steel tube columns of circular cross section:

$$
R_{b m}=R_{b}\left[1+\xi \gamma_{p}\left(\frac{\bar{\sigma}-1}{2}+\sqrt{\left(\frac{\bar{\sigma}-1}{2}\right)^{2}+10 \bar{\sigma}}\right)\right]
$$

in which $\bar{\sigma}$ - relative value of limiting transverse stress $\sigma_{b r}($ $\bar{\sigma}=\sigma_{b r} / R_{b}$ ) in the central zone of the normal section of CFSBC which is determined by the formula:

$$
\bar{\sigma}=\frac{3 \rho}{6,67+\rho} .
$$

The compressive strength of the preliminary compressed concrete core is determined by the dependence (4) and 
substituting of $R_{b}$ for the strength of concrete hardening under pressure $R_{b p}$ :

$$
R_{b p}=R_{b}+\beta \sqrt{\Delta f \sigma_{b r o}},
$$

where $\sigma_{b r o}$ - the value of preliminary lateral compression of concrete, MPa; $\beta \approx 1$ - coefficient depending on the composition of concrete mixture; $\Delta f$ - correction factor which is determined by the formula:

$$
\Delta f=0,44 / \sqrt{R_{b}} .
$$

The value of the coefficient $\beta$ should be checked by the results of the tests of the standard samples of initial concrete and pressed concrete by the formula (6).

Relative deformation $\varepsilon_{b m}$ in the vertex of the diagram of volume-compressed concrete behavior in the first approximation is determined by the formula:

$$
\varepsilon_{b m}=\varepsilon_{b 0}\left(1+0,25 \rho^{0,5}\right) \cdot\left[1+\xi \gamma_{p}\left(\frac{\bar{\sigma}+1}{2}+\sqrt{\left(\frac{\bar{\sigma}-1}{2}\right)^{2}+10 \bar{\sigma}}\right)\right](8)
$$

When the stresses in concrete have reached the vertex of the diagram with the coordinates $\left(R_{b m} ; \varepsilon_{b m}\right)$ the horizontal area, which extends to the moment of reaching the maximum permissible value by the relative deformations, is accepted. The relative deformation at the end of the diagram « $\sigma_{b z}-\varepsilon_{b z} »$ is accepted to be equal to $\varepsilon_{b 2} \leq 1,75 \varepsilon_{b m}$.

The drop-down area of the diagram is replaced by the horizontal area on the basis of the following assumptions. Limiting the relative deformations of the concrete core of CFSBC of square cross section can reach $2,5 \div 4 \%$ at the end of the drop-down area $[3,12]$. However, the operation of buildings with such deformations becomes impossible in the conditions of actual work of concrete filled steel tube structures. Therefore, it is necessary to limit the value of the relative deformation of shortening at the design stage, for example, by the value of $\varepsilon_{\mathrm{b} 2}=0,6 \%$. The value $\varepsilon_{\mathrm{bm}}$ is often within the range of $0.25-0.5 \%$. The replacement of the drop-down area by the horizontal area practically doesn't affect the accuracy of calculations due to flatness and the small length of the drop-down area.

The behavior of the steel holder can be considered for the conditions of "compression-tension" in a centrally compressed CFSBC. The diagram of its deformation is accepted in the form offered by Prandtl. Thus, the maximum stresses are determined by the formula:

$$
\sigma_{p z}=\mu_{p} R_{b}\left(\sqrt{\rho^{2}-3{\overline{\sigma_{m}}}^{2}}-\overline{\sigma_{m}}\right)
$$

in which $\overline{\sigma_{m}}-$ the relative value of the averaged transverse stress $\sigma_{b r m} / R_{b}$ in the central part of cross section of concrete core in the limiting state of CFSBC.

The value $\sigma_{b r m}$ is determined by the formula:

$$
\sigma_{b r m}=\frac{\xi \gamma_{p}}{k}\left[\frac{\bar{\sigma}-1}{2}+\sqrt{\left(\frac{\bar{\sigma}-1}{2}\right)^{2}+10 \bar{\sigma}}\right]
$$

where $k$ - coefficient of lateral pressure:

$$
k=1+9 \frac{R_{b}}{R_{b m}} .
$$

Limiting the relative deformation of the steel holder at its compression is accepted $\varepsilon_{p 2}=\varepsilon_{b 2}$ taking into account strain compatibility, and the relative deformation $\varepsilon_{p 0}$ is determined by the formula:

$$
\varepsilon_{p 0}=\sigma_{p z} / E_{s, p},
$$

where $E_{s, p}$ - modulus of elasticity of the steel holder.

In general, the diagram of the steel holder behavior in the conditions of "tension- ten-sion" is required for the second stage of strength calculation. Limiting axial stresses for this zone are determined by Mises yield criterion, which can be written for the accepted plane stress state:

$$
\alpha^{2}+\beta_{i}^{2}-\alpha \beta_{i}=1
$$

where $\alpha$ and $\beta_{i}$ - the values of limiting levels of tangential and axial stresses in the steel holder related to yield point of steel $\sigma_{y}$.

Index $i$ of the limiting level $\beta_{i}$ refers to different zones:

- $i=1$-for the zone "compression - tension";

- $i=2$-for the zone "tension - tension".

In such a formulation is first determined:

$$
\beta_{1}=\sigma_{p z} / \sigma_{y} .(14)
$$

The relative limiting level of stresses of tangential direction is determined from the equation (13):

$$
\alpha=0,5 \beta_{1}+\sqrt{1-0,75 \beta_{1}^{2}}
$$

When the value $\alpha$ is known the relative limiting level of stresses of axial direction is determined by the formula: 


$$
\beta_{2}=0,5 \alpha-\sqrt{1-0,75 \alpha^{2}}
$$

Then the limiting stress in the zone "tension - tension" is determined by the formula:

$$
\sigma_{p z}^{\prime}=\beta_{2} \cdot \sigma_{y} .(17)
$$

The developed dependences are accepted as the basis for the iterative calculation, the essence of which is stated in paper [12]. The offered calculation procedure was checked by using experimental data of testing of 66 centrally compressed and 90 eccentrically compressed samples of columns, received both as a result of our own researches and the researches of Japanese scientists [3]. Concrete filled steel box elements with different geometric and design factorswere taken:

- the width of the steel holder wall is from $120 \mathrm{~mm}$ to $324 \mathrm{~mm}$;

- the thickness of the outer steel holder wall is from $4.38 \mathrm{~mm}$ to $9.45 \mathrm{~mm}$;

- the yield point of the steel holder is from $262 \mathrm{MPa}$ to $835 \mathrm{MPa}$;

- the cylindrical strength of concrete is form $25.4 \mathrm{MPa}$ to $91.1 \mathrm{MPa}$.

As a result of this test the coefficient of variation of error vector was about $8.8 \%$, and it proves the reliability of the offered dependences.

\section{CONCLUSION}

The results of the carried out experimental researches have shown that the preliminary compression of the concrete core of concrete filled steel box columns of square cross section, which behave at eccentric compression with the relative eccentricity $e_{0} / b \leq 0,25$, noticeably increases their bearing capacity. The largest increase of bearing capacity $(25 \%)$ was obtained in the samples of pressed concrete. The increase of bearing capacity was on average $16 \%$ in the samples of self-stressing concrete.

The proposed iterative calculation procedure makes it possible to determine the strength of CFSBC of square cross-section with the accuracy sufficient for practical purposes. Moreover, this procedure can be successfully used for calculations of concrete filled steel tube elements of classical design and preliminary compressed concrete filled steel box columns.

\section{REFERENCES}

[1]. Brian U.Y. 1998: Ductility, strength and stability of concrete-filled fabricated steel box columns for tall buildings // The Structural Design of Tall Buildings, 7: 113133.

[2]. Ge.H.B. andUsami.T. 1992: Strength of concrete-filled thin-walled steel box columns // Journal of Structural Engineering, ASCE,118 (11): 3006-3054.

[3]. Nishiyama I., Morino S., Sakino K., Nakahara H. 2002: Summary of Research on Concrete-Filled Structural Steel Tube Column System Carried Out Under The US-JAPAN
Cooperative Research Program on Composite and Hybrid Structures. - Japan. $-176 \mathrm{p}$.

[4]. Nakahara H., Sacino K., Inai E. 1998: Analytical model for compressive behavior of concrete filled square steel tubular columns // Transaction of Japan Concrete Institute, 20: 171-178.

[5]. Reza Masoudnia, SoroushAmiri, W.H. WanBadaruzzaman. 2011: An Analytical Model of Short Steel Box Columns with Concrete in-Fill // Australian Journal of Basic and Applied Scienses, 5 (11): 1715-1721.

[6]. Tao Z., Uy B., Han L.H., He H.S. 2008: Design of concrete-filled steel tubular members according to the Australian Standard AS 5100 model and calibration // Australian Journal of Structural Engineering, 8(3):197-214.

[7]. Storozhenko, L.I., Ermolenko, D.A., Lapenko, O. I. 2010: Concrete filled steel tube, Poltava: TOV ACMI: 306. [8]. Ludkovskiy I.G., Fonov V.M., Kuzmenko C.M., Samarin S.I. 1982: Steel-concrete trusses madeofroll-welded profiles / / Concrete and reinforced concrete, 7: 16-19.

[9]. Nesvetaev G.V., Rezvan I.V. 2011: Evaluation of the strength of concrete filled steel tubes // Fundamental Sciences, 12: 580-583.

[10]. Krishan A.L., Troshkina E.A. 2011: Concrete filled steel tube columns with preliminary compressed concrete core // Non Traditional Cement \& Concrete: Proceedings of 4th In-ternational Conference at the University of Brno, Czech Republic on 27-30 June 2011: 293-299.

[11]. Chikhladze E.D., Arslankhanov A.D. Calculation of compressive strength of steel-concrete elements of rectangular cross section / / Concrete and reinforced concrete. - 1993. - № 3. - Pp. 13 - 15.

[12]. Krishan A.L., MelnychukA.S.Strength of concrete filled steel tube columns of square cross section: monograph- Magnitogorsk: Nosov Magnitogorsk State Technical University, 2013.-126 p.

\section{BIOGRAPHIES}

Krishan A.L.,hasreceived the Ph.D. degree from the Rostov State Building University, Russia in 2011. He is currently Professor \& Head of Department of Building Constructions at Magnitogorsk State Technical University, Russia. His research interests include design of concrete structures, concrete filled steel tube columns, methods of calculation of reinforced concrete structures.

Troshkina E.A.,has received her masters degree from the Voronezh State Architectural Building University, Russia. She is currently working as Assistant professor in the department of Building Materials and Products at Magnitogorsk State Technical University, Russia. Her research interests are in the field of self-compacting concretes, high-performance concretes, concrete filled steel tube columns.

Krishan M.A. is a student of Building Constructions department at Magnitogorsk State Technical University, Russia. Her research interests include development of calculation procedure of concrete filled steel tube columns. 